\title{
JOHN GABRIEL STEDMAN
}

(Eenige aanteekeningen omtrent zijn geslacht, loopbaan en werkkring)

DOOR

\section{K. KESLER}

In 1796 verscheen in Londen bij de uitgevers J. Johnson, Saint Paul's Churchyard, en J. Edwards, Pall Mall, een werk van den luitenant-kolonel op non-activiteit John Gabriel Stedman, die in hetzelfde jaar werd bevorderd tot kolonel en belast werd met het commando over een Britsch linie-regiment, in garnizoen te Gibraltar. Een ongeval, dat hem kort na deze promotie overkwam, verhinderde hem, zich naar zijn garnizoen te begeven en noodzaakte hem, ontslag uit den militairen dienst te nemen. Dit werk verwekte destijds groote belangstelling in Holland en elders, wat o.a. blijkt uit bewerkingen ervan in het Hollandsch, Fransch en Duitsch en ook uit de inteekenaars er op. Hieronder toch komen voor Prins Willem V, de generaal Robert Douglas, drie kolonels van de voormalige Schotsche Brigade in de Republiek der Vereenigde Nederlanden en een aanzienlijk aantal andere officieren en autoriteiten.

De titel van het boek is eenigszins misleidend, ,Narrative of a Five Years' expedition against the Revolted Negroes of Surinam from 1772 to 1777 '. Vooreerst toch bevat het, behalve een verhaal van de verrichtingen van het corps, dat in 1772 onder commando van den kolonel Louis Henry Fourgeoud werd uitgezonden, om een einde te maken aan de strooptochten van weggeloopen slaven in het plantage-gebied, nog allerlei beschrijvingen van menschen, dieren en planten en ten slotte daardoorheen gevlochten, een verslag van des schrijvers amourettes met de schoone mulattin Johanna. Een expeditie van vijf jaren kan men de verschillende tochten van het corps naar het binnenland, die door langdurige periodes van werkloosheid werden onderbroken, 
moeilijk noemen, terwijl het niet ging tegen opgestane negers, maar tegen wegloopers, die op de plantages trachtten te rooven, wat in het binnenland niet te verkrijgen was, voedsel, wapenen en vrouwen. De verhouding tot Johanna wordt op eenigszins sentimenteele wijze beschreven en, hoewel daaruit een zoon werd geboren, die later, vrijverklaard, dienst nam bij de Britsche marine en als adelborst stierf, zat zij den schrijver toch niet bijster diep. Kort na zijn terugkeer naar Holland toch - hij was, behalve de commandant de eenige der in 1772 vertrokken officieren, die levend terugkeerde - huwde hij met Adriana Wiertz van Coehoorn, een verre verwante van den beroemden vesting-bouwkundige Menno van Coehoorn 1).

Het is dus geenszins als nutteloos te beschouwen, dat de schrijver in den volledigen titel van het boek op 18e-eeuwsch wijdloopige manier opsomt, wat het boek verder nog zal bevatten. De titel luidt volledig aldus: Na het woord Surinam volgt nog ter verdere inlichting:

,,in Guiana on the Wild Coast of South America, from the year 1772 to 1777 , elucidating the History of that Country and

describing its Productions, viz.

Quadrupedes, Birds, Fishes, Reptiles, Trees, Shrubs, Fruits and Roots

with an Account of the Indians of Guiana and Negroes of Guinea,

by Capt. J. G. Stedman,

illustrated with 80 elegant Engravings from drawings made by the author.

De schrijver van dit boek was een afstammeling uit een oud Schotsch geslacht, waarvan de geschiedenis bekend is tot in de

1) In de registers van het Regt. Stuart der Schotsche Brigade is deze aanteekening daaromtrent te vinden:

1782 Febr. 2 Mar. at Maestricht Major John A. Stedman to Miss A. Wartz of that place.

Hierin zijn blijkbaar twee verschrijvingen geschied. John A. Stedman moet natuurlijk zijn John G. Stedman en de naam der bruid was niet Wartz, maar Wiertz.

Stedman vermeldt in zijn boek in zeer pathetische bewoordingen, dat hij op 5 Augustus 1783 bericht ontving, dat Johanna in Suriname op 5 November 1782, dus negen maanden na zijn huwelijk met freule Wiertz van Coehoorn overleden was. 
16e eeuw. De meeste leden van dit geslacht waren òf krijgslieden, of predikanten van de Schotsche kerk; een enkele ook voer ter zee en vestigde zich later als reeder aan land. Eigenaardig is het wel, dat de naam van dit geslacht, waartoe verscheidene bekende Schotten behooren en dat behalve afstammelingen in het land van oorsprong ook vertakkingen heeft in ons land en in Duitschland, eigenlijk niet Stedman, maar Barton behoorde te zijn. Charles Barton toch, de zoon van Andrew Barton 1), huwde in de 16e eeuw met Susan, de dochter van Charles Stedman en zijn vrouw Janet Neilson van Leith. De bruid bezat belangrijke eigen-

1) Andrew Barton, Schotsch admiraal ( ?-1511) wordt, naar het schijnt ten onrechte wel aangeduid als Sir Andrew Barton. Er zijn echter geen aanwijzingen, dat hij in den adelstand is verheven en in 1510 wordt een schenking van land aan hem in het graafschap Fife vermeld zonder titel. Hij was een zoon van John Barton, een koopvaarder, wiens drie zoons Andrew, Robert en John hetzelfde beroep uitoefenden. In 1746 werden door Jacobus III, koning van Schotland, aan de Bartons kaperbrieven verleend tegen de Portugeezen, die een schip van John Barton Sr. genomen en uitgeplunderd hadden. Eenige malen werden deze kaperbrieven ingetrokken, maar in 1506 werden zij hernieuwd met vergunning, de schadeloosstelling vol te houden tot een bedrag van 12.000 Portugeesche ducaten bereikt zou zijn. Andrew Barton toonde zich de meest actieve der gebroeders en raakte daardoor zeer in de gunst bij koning Jacobus IV, die in 1488 zijn vader was opgevolgd, en die evenveel belang in maritieme zaken stelde als in tournooien, met welke laatste hij in geheel Europa roem behaalde. De koning stelde een groot schip ter beschikking van Barton, die daarmede de zee zuiverde van zeeroovers van allerlei nationaliteit. Dit deed hij zoo grondig, dat hij ten bewijze daarvan drie vaten met afgehakte hoofden aan den koning kon zenden. Deze droeg hem verder o.a. op, Denemarken in zijn strijd tegen Lubeck hulp te verleenen en toen de landvoogdes Margaretha van Savoye een klacht tegen de Bartons indiende wegens het nemen van Vlaamsche schepen, werd deze door den koning afgewezen met het antwoord, dat de Bartons geen zeeroovers waren. Het optreden der gebroeders bracht intusschen ook aan den Engelschen handel schade toe, daar zij ook Engelsche schepen doorzochten, die van Portugal kwamen. Op aandrang van Sir Thomas en Sir Edward Howard gaf Hendrik VIII daarom vergunning Barton aan te vallen. In 1511 werd Bartons schip ,"The Lion" na een verwoed gevecht in The Downs genomen en naar de Theems opgebracht. Andrew Barton was tijdens het gevecht door een boogschutter gedood. Een klacht hierover door Jacobus IV tot Hendrik VIII gericht, werd door dezen beantwoord met de opmerking, dat ,,the fate of pirates was never an object of dispute among princes". Dit en andere geschillen gaven aanleiding tot een oorlog tusschen Schotland en Engeland, tijdens welken Jacobus IV in den beroemden slag bij Flodden (9 Sept. 1512) sneuvelde. 
dommen en na het huwelijk nam de echtgenoot den naam zijner vrouw aan. Zoo trad de naam Stedman in plaats van dien van Barton. Dit geschiedde in de 16e eeuw, toen dus Schotland en Engeland nog afzonderlijke koninkrijken waren, Schotland onder de Stuarts en Engeland onder de Tudors. Een eeuw later ongeveer zou de eerste Stedman in betrekking komen tot Holland, het land, waar later velen der Stedmans het terrein hunner werkzaamheid zouden vinden.

Die eerste vertegenwoordiger van het geslacht Stedman, die naar Holland kwam, was Robert Stedman (1667-1738). Hij voer aanvankelijk als gezagvoerder en eigenaar met een schip tusschen Borrowstownness in Schotland en Holland. Deze reizen, die weldra uitgestrekt werden totDenemarken,Noorwegen en Zweden, leverden zooveel voordeel op, dat Stedman later in het bezit was van niet minder dan 13 schepen. Ten slotte troffen hem echter ernstige tegenspoeden, waardoor hij zijn verzamelde rijkdommen weer verloor.

Niet lang daarna begaf zich een andere Stedman naar Holland, ditmaal als vluchteling. Drie zoons toch van den bovengenoemden Robert Stedman kozen de zijde van den Jongen Pretendent Karel Eduard, toen deze zich in Juli 1745 in Schotland vertoonde. Na diens nederlaag bij Culloden op 27 April 1746 moesten hijzelf en zijn aanhangers de vlucht nemen. Van de drie gebroeders Stedman wisten twee, Alexander en Charles, naar Amerika, de derde, John, naar Rotterdam te ontkomen, vanwaar de laatste later naar Schotland terugkeerde.

Weldra zouden de Stedmans in nauwere aanraking met onze Republiek komen. Een broeder van bovengenoemden Robert Stedman toch was in 1699 predikant te Dalmeny in het graafschap Fife en werd in 1710 overgeplaatst naar de Tron-church te Edinburg. Deze predikant had een talrijk gezin; uit zijn huwelijk met Jean Kinnaird werden drie zoons, Robert, Alexander en John en zes dochters geboren. De oudste zoon Robert trad in 1730 als vaandrig in dienst bij de z.g. Schotsche brigade van het leger onzer Republiek.

Deze Schotsche brigade (Scots Brigade) was een afzonderlijk onderdeel van het Staatsche leger, waarvan de geschiedenis teruggaat tot het eerste gedeelte van den 80 -jarigen oorlog en zich uitstrekt tot het laatste gedeelte van de $18 \mathrm{e}$ eeuw en wel tot 
het jaar 1782. Fransche, Waalsche, Schotsche en andere hulptroepen namen, zooals bekend is, deel aan den strijd van de opgestane gewesten tegen Spanje, o.a. bij de verdediging van Den Briel, van Haarlem en andere steden en bij verschillende gevechten. Wat de Schotten betreft, waren er in dien tijd verschillende afzonderlijke compagnieën in dienst, elke onder commando van een eigen kapitein. Omstreeks 1573 schijnen deze tot een geheel vereenigd te zijn onder bevel van een zekeren kolonel Ormis en in 1586 werden de Schotsche compagnieën samen gevoegd tot twee regimenten respectievelijk onder commando van de kolonels Balfour en Patten. Naar gelang van de talrijkheid der hulptroepen waren er in den loop der jaren soms vier of meer regimenten Schotten in dienst, maar meestal bepaalde zich het aantal tot twee, ieder van 10 compagnieën. Iedere compagnie bestond gewoonlijk uit 150 man, waarvan in den tijd van Maurits 100 musketiers en 50 piekeniers. In den loop der jaren werd de bewapening natuurlijk gewijzigd; tegen het einde der 17e eeuw verdwenen de piekeniers, de vroegere arquebusiers of busschieters waren reeds vervangen door musketiers, enz. Ook de verdere uitrusting van officieren en minderen, die door Prins Maurits voor de onder zijn bevel staande troepen in 1589 was voorgeschreven, werd in den loop der jaren belangrijk gewijzigd. Eén der voorrechten, waarop de Schotten steeds zeer gesteld waren, was, dat hun uniformen hoofdzakelijk het nationale rood zouden vertoonen. Dit voorrecht heeft de brigade tot haar oplossing in het leger der Republiek mogen behouden. Ook de regimentsvaandels die o.a. het St.-Andries-kruis en den Schotschen distel vertoonden, bleven tot dien tijd behouden 1). Afbeeldingen uit het laatst der 18 e eeuw van soldaten der brigade doen zien, dat zij, wat betreft het regiment van den kolonel John Stuart, waartoe de Stedmans behoorden, gekleed waren in een rooden rok met gele voering, geel vest en broek en tot over de knieën reikende witte slobkousen. Het hoofddeksel bestond voor de infanterie uit een van achteren opgeslagen hoed, terwijl de haren lang gedragen werden en tot een op den rug hangenden staart waren samengevlochten. Grenadiers droegen in plaats van dezen hoed

1) Deze vaandels worden tegenwoordig bewaard in St.-Gile's Church te Edinburgh. Behalve de gekroonde Schotsche distel en het St.Andrieskruis vertoonen zij het opschrift: NEMO ME IMPUNE LACESSIT (Niemand tergt mij straffeloos), het motto van de Schotsche kroon en van al de Schotsche regimenten, overeenkomende met dat van het Schotsche volk: ,Wha dare meddle wi' me?" (W. F. H. King, Classical and foreign quotations). 
een hoogen haren soort kolbak de z.g. zwarte of donker grijze grenadiersmuts. De bwapening bestond uit geweer met bajonet, korten sabel en op den rug gedragen patroontasch.

Bij dit corps trad, zooals boven gezegd werd, de oudste zoon van den predikant John Stedman, Robert in 1730 in dienst. Hij was in 1701 geboren en was dus destijds 29 jaar oud. Tot zijn overlijden in 1770 te Breda bleef hij in Nederlandschen dienst en bereikte na de verschillende rangen in de brigade doorloopen te hebben, dien van luitenant-kolonel. Hij was o.a. tegenwoordig bij de slagen bij Fontenoy (1745) en Rocoux (1746) en bij de belegeringen van Dendermonde en Bergen-op-Zoom (1747). Uit zijn huwelijk met Antoinette Christina van Ceulen werden twee zoons geboren, John Gabriel in 1744 en William George in 1748. Beiden volgden het voorbeeld van hun vader en traden bij de Schotsche brigade in dienst, waarin zij bij het regiment van den kolonel John Stuart werden ingedeeld.

De geschiedenis van het corps, althans wat zijn diensten aan de Republiek bewezen, betreft, liep echter ten einde. George III had den wensch te kennen gegeven, over de brigade te kunnen beschikken in den strijd tegen de opgestane Amerikaansche koloniën; onderhandelingen hierover leidden niet tot eenig resultaat en de brigade bleef voorloopig in Holland. Tijdens den Vierden Engelschen oorlog echter namen de Staten-Generaal in 1782 het besluit, dat de brigade als zelfstandig onderdeel van de troepen in dienst der Republiek zou ophouden te bestaan en met ingang van 1 Januari 1783 geheel in het Staatsche leger zou worden opgenomen. De officieren moesten een eed van trouw aan de Staten van Holland 1) afleggen, en moesten tevens hun trouw aan GrootBrittannië voor altijd herroepen. Verder werden er belangrijke wijzigingen in de uniformen gebracht, de vaandels zouden van Schotsche in Hollandsche veranderd worden, de officieren zouden voortaan oranje sjerpen dragen, kortom aan het zelfstandige karakter van de brigade, als Schotsche hulptroep, dat zij tot dusver steeds gehad had, werd voor goed een einde gemaakt.

Aan deze voorwaarden weigerden een groot aantal der officieren, zich te onderwerpen. Vijf en vijftig hunner vroegen en verkregen eervol ontslag uit den Hollandschen dienst en keerden

1) De Schotsche regimenten stonden gewoonlijk ,,ter repartitie” van Holland; enkele ontvingen hun bezoldiging soms geheel of gedeeltelijk van andere gewesten b.v. Gelderland of Zeeland. 
naar Engeland terug, waar zij voorloopig op non-activiteit gesteld werden. In 1793 besloot George III, de Schotsche brigade als onderdeel van het Britsche leger opnieuw in het leven te roepen; als zoodanig bestaat zij thans nog.

Onder de repatrieerende officieren was ook John Gabriel Stedman; zijn broeder William George besloot in de Republiek te blijven en liet zich als onderdaan daarvan naturaliseeren. Hij ging over in het leger der Republiek en verliet in 1796 als majoor den dienst met een pensioen van $f$ 1000.- p. j. Hij overleed te Nijmegen. Uit zijn huwelijk met Charlotte Margarethe Haltmann was in 1778 te Zutfen een zoon geboren, John Andrew, die op $18 \mathrm{e}$-eeuwsche manier reeds als kind tot officier werd aangesteld. Op 16-jarigen leeftijd deed hij voor het érst actieven dienst onder den Hertog van York en den Prins van Oranje aan de Noordgrens van Frankrijk (1794). Vijf jaar later streed hij, ditmaal tegen den Hertog van York tijdens den Engelsch-Russischen inval in Noord-Holland bij Bergen (10 September 1799) en later in 1809 op Walcheren eveneens tegen de Engelschen. Tijdens de inlijving bij Frankrijk diende hij als brigade-generaal in het Fransche leger en nam als zoodanig gedurende twee jaren deel aan de krijgsbedrijven in Italië en aan de slagen bij Bautzen en bij Dresden (1813). In 1814 sloot hij zich bij de Oranje-partij aan en commandeerde in 1815 als luitenant-generaal de Hollandsche reserve bij Waterloo. Hij overleed in 1833 te Nijmegen. Uit zijn huwelijk met Nicola Geertruida van de Poll, een kleindochter van den laatsten burgemeester van Amsterdam vóór de inlijving 1) werd een zoon Charles geboren, die zich later bij Coblentz vestigde en zich als Duitsch onderdaan liet naturaliseeren. Als Baron Barton von Stedman werd hij in den Pruisischen adel opgenomen. Hierbij kwam dus weder de oorspronkelijke naam Barton in eere.

1) Mr. Jan Wolters van de Poll was 1808-1810 burgemeester van Amsterdam. Hij was een zoon van Mr. Jacobus van de Poll en Cornelia Jacoba Wolters. Het geslacht Van de Poll, dat in de $18 \mathrm{e}$ eeuw een vooraanstaande plaats in Amsterdam innam, stamde af van Gijsbert Jan van de Poll, een zoon van Jan Gijsbert van de Poll, die in 1538 burgemeester van Montfoort was. Gijsbert Jan van de Poll vestigde zich als houthandelaar te Amsterdam.

In de $18 \mathrm{e}$ eeuw was het bankiershuis Harman van de Poll \& Co. voor belangrijke bedragen in Suriname geinteresseerd, o.a. door de oprichting van twee belangrijke negotiatiën ten laste van planters in Suriname, respectievelijk in 1765 en 1769 en geheeten Letter A en Letter C. 


\section{Literatur o.a.:}

Dictionary of National Biography, LIV, p. 127 e.v.

William Anderson, The Scottish Nation III, Edinburgh 1863.

James Ferguson, Papers illustrating the History of the Scots Brigade.

\section{$\mathrm{Naschrift}$}

Of Andrew Barton van adel was met den titel „,knight”, waardoor hij er aanspraak op zou gehad hebben, als Sir Andrew betiteld en aangesproken te worden, is zeer twijfelachtig, zoo niet onwaarschijnlijk. Evenmin wordt vermeld, dat hij deze waardigheid zou verkregen hebben, doordat hij ridder geworden was door opneming in een der Britsche of, waarschijnlijker, Schotsche orden. De eenige maal, dat hij als Sir Andrew en als ,knight” vermeld wordt, is in een oude ballade, medegedeeld door William Anderson in THE SCOTTISH NATION (I. p. 257) ed. 1863, waarin eenige malen de naam Sir Andrew voorkomt met den titel „,knight”, b.v. aldus:

Hast thou not heard, now Henryc Hunt, As thou hast sailed by daye and night, Of a Scottish rover on the seas, Men call him Sir Andrew Barton, knight?

In datzelfde werk vindt men op p. 263 omtrent den naam Barton het volgende:

Barton is vermoedelijk oorspronkelijk geweest Bereton, d.w.z. een boerderij, waar ,,bere” of ,,barley” (gerst) verbouwd wordt. Andere afleidingen zijn echter ook mogelijk.

Oorspronkelijk is Barton een Engelsche (niet een Schotsche) 'naam. Oude familiën van dien naam leefden in Lancashire met vertakkingen in Ierland en Schotland. Eén familie Barton, eveneens uit Lancashire afkomstig, die zich later in Chester vestigde, wordt reeds in 1567 vermeld.

Uit dit alles volgt, dat de Stedmans, die eigenlijk Barton behoorden te heeten, van zeer oude Britsche afstamming zijn. 